\title{
Molecular mechanisms underlying the antidepressant actions of arketamine: beyond the NMDA receptor
}

\author{
Yan Wei $\mathbb{C}^{1,2} \cdot$ Lijia Chang $^{1} \cdot$ Kenji Hashimoto $\mathbb{1}^{1}$ \\ Received: 8 February 2021 / Revised: 1 April 2021 / Accepted: 13 April 2021 / Published online: 7 May 2021 \\ (c) The Author(s) 2021. This article is published with open access
}

\begin{abstract}
The discovery of robust antidepressant actions exerted by the $N$-methyl-D-aspartate receptor (NMDAR) antagonist $(R, S)$ ketamine has been a crucial breakthrough in mood disorder research. $(R, S)$-ketamine is a racemic mixture of equal amounts of $(R)$-ketamine (arketamine) and (S)-ketamine (esketamine). In 2019, an esketamine nasal spray from Johnson \& Johnson was approved in the United States of America and Europe for treatment-resistant depression. However, an increasing number of preclinical studies show that arketamine has greater potency and longer-lasting antidepressant-like effects than esketamine in rodents, despite the lower binding affinity of arketamine for the NMDAR. In clinical trials, non-ketamine NMDARrelated compounds did not exhibit ketamine-like robust antidepressant actions in patients with depression, despite these compounds showing antidepressant-like effects in rodents. Thus, the rodent data do not necessarily translate to humans due to the complexity of human psychiatric disorders. Collectively, the available studies indicate that it is unlikely that NMDAR plays a major role in the antidepressant action of $(R, S)$-ketamine and its enantiomers, although the precise molecular mechanisms underlying antidepressant actions of $(R, S)$-ketamine and its enantiomers remain unclear. In this paper, we review recent findings on the molecular mechanisms underlying the antidepressant actions of $(R, S)$-ketamine and its potent enantiomer arketamine. Furthermore, we discuss the possible role of the brain-gut-microbiota axis and brain-spleen axis in stress-related psychiatric disorders and in the antidepressant-like action of arketamine. Finally, we discuss the potential of arketamine as a treatment for cognitive impairment in psychiatric disorders, Parkinson's disease, osteoporosis, inflammatory bowel diseases, and stroke.
\end{abstract}

\section{Introduction}

Depression is a common psychiatric disorder affecting more than 264 million people from teenagers through to older adults $[1,2]$. The World Health Organization reports that $\sim 800,000$ people die from suicide every year, indicating a serious global public health problem. Delayed effects (lag time) and treatment failure through high nonresponse

Kenji Hashimoto

hashimoto@faculty.chiba-u.jp

1 Division of Clinical Neuroscience, Chiba University Center for Forensic Mental Health, Chiba, Japan

2 Key Laboratory of Medical Electrophysiology of Ministry of Education and Medical Electrophysiological Key Laboratory of Sichuan Province, Collaborative Innovation Center for Prevention and Treatment of Cardiovascular Disease, Institute of Cardiovascular Research, Southwest Medical University, Luzhou, Sichuan, China rates are the disadvantages of existing antidepressants such as selective serotonin-reuptake inhibitors and serotonin norepinephrine-reuptake inhibitors [3, 4]. Therefore, the development of rapid-acting antidepressants that are also effective in treatment-resistant depression is of great importance.

Abnormalities in glutamatergic neurotransmission via the $N$-methyl-D-aspartate receptor (NMDAR) play a role in the pathogenesis of mood disorders, including major depressive disorder (MDD) and bipolar disorder (BD) [5-15]. The serendipitous discovery of robust antidepressant effects exerted by the NMDAR antagonist $(R, S)$-ketamine was a paradigm shift in the research of mood disorders [16-18]. In 2000, Berman et al. [19] demonstrated that a single intravenous infusion of $(R, S)$-ketamine $(0.5 \mathrm{mg} / \mathrm{kg})$ acted within hours to cause rapid antidepressant effects in patients $(n=7)$ with MDD that were sustained for up to $72 \mathrm{~h}$ after treatment. Many subsequent studies showed that a single or repeated intravenous infusions of $(R, S)$-ketamine $(0.5 \mathrm{mg} / \mathrm{kg})$ produced robust antidepressant and antisuicidal effects in patients with 
treatment-resistant MDD or BD [20-28]. Furthermore, beneficial effects of $(R, S)$-ketamine were also exhibited in patients with treatment-resistant post-traumatic stress disorder (PTSD) [29, 30]. Despite the lack of long-term data on efficacy and limited data on safety, off-label use of $(R, S)$ ketamine is increasing in the United States of America (USA) and Europe [31-33].

In 2019, a Johnson \& Johnson nasal spray containing the ketamine enantiomer $(S)$-ketamine (esketamine) was approved in the USA and Europe for treatment-resistant depression $[34,35]$, although several concerns about the efficacy and the approval were raised $[36,37]$. We have proposed that the alternative ketamine enantiomer, $(R)$-ketamine (arketamine), may be a safer antidepressant than $(R, S)$-ketamine and esketamine [38-44].

The molecular mechanisms underlying the antidepressant actions of $(R, S)$-ketamine remain poorly understood. Previously, we published review articles on the mechanisms underlying the antidepressant action of ketamine and its enantiomers [41-44]. Since these reviews were published, new studies have shed further light on the molecular mechanisms of ketamine's antidepressant effects. Here we review the recent findings on molecular mechanisms underlying the antidepressant actions of $(R, S)$-ketamine and its enantiomers. We also discuss the possible role of the brain-gut-microbiota and brain-spleen axes in stress-related psychiatric disorders and in the antidepressant-like action of arketamine. Finally, we discuss the potential of arketamine for the treatment of nonpsychiatric disorders.

\section{Beyond NMDAR inhibition}

\section{Preclinical findings using two enantiomers}

In 1975, the first study showing antidepressant-like effects of $(R, S)$-ketamine in rodents was published, reporting an amelioration of phenotype in classic animal models such as tetrabenazine-induced ptosis, reserpine-induced hypothermia, yohimbine toxicity, and oxotremorine-induced tremors [45]. $(R, S)$-ketamine (inhibition constant $\mathrm{Ki}=$ $0.53 \mu \mathrm{M}$ for NMDAR) is a mixture of equal amounts of arketamine $(\mathrm{Ki}=1.4 \mu \mathrm{M}$ for NMDAR) and esketamine ( $\mathrm{Ki}=0.30 \mu \mathrm{M}$ for NMDAR) (Fig. 1) [46]. We previously reported that arketamine exhibited greater potency and longer-lasting antidepressant-like effects than esketamine in the neonatal dexamethasone exposure, chronic social defeat stress (CSDS), and learned helplessness (LH) rodent models of depression [47, 48]. The superior effect of arketamine compared to esketamine in rodents was subsequently replicated [49-52]. Furthermore, arketamine acted with greater potency than esketamine for depressionlike behaviors in an organophosphate-exposed rat model of Gulf War illness [53].

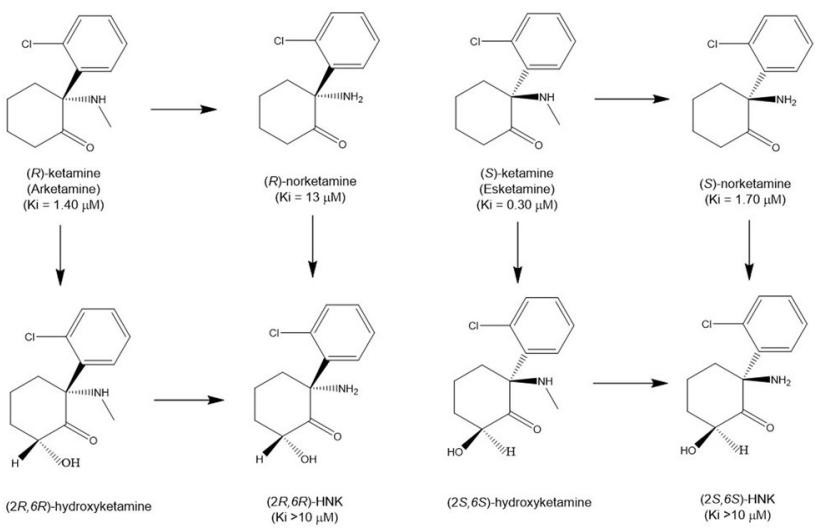

Fig. 1 Major metabolisms of ketamine enantiomers. Arketamine is metabolized to $(R)$-norketamine that is metabolized to $(2 R, 6 R)$ hydroxynorketamine (HNK). In addition, arketamine is also metabolized to $(2 R, 6 R)$-hydroxyketamine that is metabolized $(2 R, 6 R)$-HNK. Esketamine is metabolized to $(S)$-norketamine that is metabolized to $(2 S, 6 S)$-HNK. In addition, esketamine is metabolized to $(2 S, 6 S)$ hydroxyketamine that is metabolized to $(2 S, 6 S)$-HNK. Ki values for NMDAR are presented in parenthesis [46, 49].

Behavioral abnormalities in rodents (hyperlocomotion, prepulse inhibition, and abuse liability) were induced less by arketamine than by esketamine [48, 52]. Furthermore, repeated intermittent administration of esketamine, but not arketamine, in mice caused a reduction in parvalbumin (PV) immunoreactivity in the prefrontal cortex (PFC) [54] and an increase in locomotion after methamphetamine administration [55]. These findings suggest a risk for psychosis in subjects administered repeated doses of esketamine. A single intravenous injection of esketamine $(0.5 \mathrm{mg} / \mathrm{kg})$, but not arketamine $(0.5 \mathrm{mg} / \mathrm{kg})$, reduced the binding availability of the dopamine $\mathrm{D}_{2 / 3}$ receptor in the conscious monkey striatum [56], suggesting that esketamine, but not arketamine, can cause dopamine release in the striatum. Thus, it has been suggested that esketamineinduced dopamine release from presynaptic terminals is associated with the psychotomimetic and dissociative effects of esketamine in humans. Collectively, data from preclinical studies suggest that arketamine elicits fewer side effects than esketamine. Indeed, it was suggested that the side effects of $(R, S)$-ketamine are associated with esketamine but not arketamine [57].

Masaki et al. [58] used functional MRI (fMRI) to investigate the response of the conscious rat brain to $(R, S)$-ketamine, its two constituent enantiomers, and the potent selective NMDAR antagonist (+)-MK-801. The positive fMRI response observed in the rat brain following a single injection of $(R, S)$-ketamine $(10 \mathrm{mg} / \mathrm{kg})$ or esketamine $(10 \mathrm{mg} / \mathrm{kg})$ was similar to the positive response observed following $(+)$-MK$801(0.1 \mathrm{mg} / \mathrm{kg})$ injection. In contrast, a single injection of arketamine $(10 \mathrm{mg} / \mathrm{kg})$ in the rat brain elicited a negative fMRI response. Thus, it is possible that the pharmacological 
action of $10 \mathrm{mg} / \mathrm{kg}$ arketamine, a dose capable of exerting antidepressant effects, is not dependent upon NMDAR inhibition [58]. Furthermore, other mechanisms to counteract the NMDAR inhibition-induced brain activation may exist in the negative fMRI response to arketamine; however, further study in this area is needed. The findings of Masaki et al. [58] were supported by data showing the arketamine- and esketamine-induced opposite patterns of cerebral glucose utilization in the healthy human brain [59]. Importantly, the pharmacokinetic profile of the two ketamine enantiomers was similar $[49,50]$, indicating that pharmacokinetic differences do not underlie the difference in the potency of the two ketamine enantiomers [41, 44]. Furthermore, $(R, S)$-ketamine was reported to exert NMDAR-independent, cAMPdependent antidepressant-like actions [60]. Taken together, these data indicate it is unlikely that NMDAR inhibition plays a major role in the antidepressant-like actions of arketamine in rodents.

\section{Preclinical findings using ketamine metabolites}

Ketamine is metabolized to the intermediate norketamine (its major metabolite, $80 \%$ ) via hydroxylation, or can also be metabolized to 4- and 5-hydroxyketamine (5\%). Norketamine is converted to 4-, 5-, and 6-hydroxynorketamine (HNK) (15\%), making HNKs and hydroxyketamines minor metabolites [44, 61-63]. In 2016, Zanos et al. [49] demonstrated that $(2 R, 6 R)-\mathrm{HNK}(\mathrm{Ki}>10 \mu \mathrm{M}$ for NMDAR) (Fig. 1) derived from arketamine was necessary for the antidepressantlike effects of $(R, S)$-ketamine, and that NMDAR inhibition does not play a role in the antidepressant-like effects of ( $2 R, 6$ $R$ )-HNK since it does not bind to NMDAR [49]. In contrast, we argued that $(2 R, 6 R)$-HNK, unlike its parent compound arketamine, did not show potent antidepressant-like effects in rodent models of depression, including CSDS and LH models [64-67]. Treatment with two cytochrome P450 (CYP) inhibitors, ticlopidine hydrochloride and 1-aminobenzotriazole, prior to arketamine administration, increased the plasma levels of arketamine, but almost completely blocked generation of $(2 R, 6 R)-\mathrm{HNK}$. It should be noted that the dose at which arketamine produced antidepressant-like effects was lower in the presence of CYP inhibitors than in their absence, which is consistent with antidepressant-like effects being dependent upon exposure levels of arketamine but not $(2 R, 6 R)$-HNK [68]. Importantly, $(R)$-norketamine is a major metabolite of arketamine, while $(2 R, 6 R)-\mathrm{HNK}$ is a minor metabolite [68]. If $(2 R, 6 R)-\mathrm{HNK}$ is responsible for the antidepressant-like effects of $(R, S)$-ketamine, higher doses of $(2 R, 6 R)$-HNK are needed to cause antidepressant-like effects in rodents [44].

The direct infusion of arketamine into the medial PFC and hippocampus caused antidepressant-like effects in a rat $\mathrm{LH}$ model, suggesting that arketamine itself, but not its metabolites, is responsible for causing antidepressant-like effects [69]. Furthermore, ( $2 R, 6 R)$-HNK (10 or $20 \mathrm{mg} / \mathrm{kg}$ ) did not cause antidepressant-like effects in the repeated corticosterone injection model [70]. From the relationship between antidepressant-like effects and brain concentrations of $(2 R, 6 R)$-HNK, Chaki and Yamaguchi [71] conclude that generation of $(2 R, 6 R)$-HNK is not necessary for the antidepressant action of $(R, S)$-ketamine. Taken together, these data indicate that the generation of $(2 R, 6$ $R$ )-HNK from arketamine is not essential for the antidepressant-like effects of $(R, S)$-ketamine or arketamine [41-44, 71-74].

Antidepressant-like effects of $(2 R, 6 R)$-HNK in chronic corticosterone-treated model, CSDS model, chronic restraint stress model, and modified LH model were demonstrated $[49,75]$. In contrast, several groups reported antidepressantlike effects of $(2 R, 6 R)$-HNK in naive rodents without a depression-like phenotype, although the effects of the parent compound arketamine were not compared in the same model $[76,77]$. Importantly, in healthy control subjects, $(R, S)$ ketamine caused depressive symptoms such as anhedonia rather than antidepressant effects [78]. Thus, the use of rodents without depression-like phenotypes may lead to misinterpretation of the antidepressant-like effects of $(R, S)$ ketamine and ketamine-like candidates [79].

Esketamine is metabolized to $(S)$-norketamine $(\mathrm{Ki}=1.07$ $\mu \mathrm{M}$ for NMDAR) (Fig. 1) [46] and subsequently converted to (2S,6S)-HNK (Fig. 1). We reported that $(S)$-norketamine produced rapid and sustained antidepressant-like effects in mouse models of depression, with a potency similar to that of esketamine [80]. However, the antidepressant-like effects of $(S)$-norketamine were still less potent than those of arketamine. Antidepressant-like effects of $(S)$-norketamine were also reported in the repeated corticosterone-treated model [70]. (S)-norketamine did not cause the behavioral and biochemical abnormalities such as prepulse inhibition deficits, reward effects, loss of PV immunoreactivity in the PFC, and baseline $\gamma$-band oscillation increase that have been observed with esketamine [80]. Esketamine shares the serious detrimental side effects of $(R, S)$-ketamine, such as psychotomimetic and dissociative effects as well as abuse liability. These data support that NMDAR may not play a major role in antidepressant-like effects of (S)-norketamine, while it may be related to side effects. Collectively, these data suggest that $(S)$ norketamine would be a safer antidepressant than esketamine [81]. In addition, it is noteworthy that $(S)$-norketamine is not a scheduled compound and could be brought by depressed patients to their home.

\section{Clinical findings}

It has been recognized that a major pharmacological effect of $(R, S)$-ketamine is NMDAR antagonism, and that this 
inhibition plays a major role in the antidepressant action of $(R, S)$-ketamine [16, 17]. Several pharmaceutical companies developed novel NMDAR antagonists and modulators to trial as antidepressant candidates without the side effects of ketamine. However, the non-ketamine NMDAR ligands memantine, rapastinel, lanicemine, traxoprodil, and L-4chlorokynurenine $(\mathrm{AV}-101)$ did not mimic the robust antidepressant actions of ketamine in patients with MDD $[24,25,41-44,82]$. Importantly, it is well known that the potent selective NMDAR antagonist (+)-MK-801 did not cause antidepressant actions in patients with MDD [unpublished data of Merck, 44], although (+)-MK-801 had rapid antidepressant-like effects in a preclinical CSDS model [83]. Thus, it seems that the use of behavioral tests in rodent models of depression may not predict antidepressant effects in depressed patients, as the full complexity of human depression cannot be appropriately mimicked in rodents [84].

A recent meta-analysis concluded that intravenous $(R, S)$ ketamine appears more efficacious than intranasal esketamine for the treatment of depression [85], although the route of administration is different. A head-to-head study of intravenous esketamine $(0.25 \mathrm{mg} / \mathrm{kg})$ and $(R, S)$-ketamine $(0.5 \mathrm{mg} / \mathrm{kg})$ in Brazil found that both compounds exerted similar antidepressant effects in patients with treatment-resistant MDD; however, the sustained antidepressant effects of $(R, S)$ ketamine were more potent than those of esketamine at seven days after injection, albeit without statistical significance $(P=$ 0.08) [86]. Furthermore, an open-label study in Brazil demonstrated that a single intravenous infusion of arketamine $(0.5 \mathrm{mg} / \mathrm{kg})$ caused rapid and sustained antidepressant effects in patients with treatment-resistant MDD, although sample size $(n=7)$ was small [87]. A recent randomized, placebocontrolled, crossover study of $(R, S)$-ketamine $(0.5 \mathrm{mg} / \mathrm{kg})$ in patients with treatment-resistant MDD showed an inverse relationship between ( $2 R, 6 R ; 2 S, 6 S)$-HNK concentration and antidepressant response [88], suggesting that $(2 R, 6 R)-\mathrm{HNK}$ might not contribute to the antidepressant action of $(R, S)$ ketamine [89]. A phase 1 study of $(2 R, 6 R)-\mathrm{HNK}$ in healthy control subjects $(0.1-4.0 \mathrm{mg} / \mathrm{kg}$, intravenous administration for $40 \mathrm{~min}$, NCT04711005) is underway at Duke University (sponsored by the National Institute of Mental Health, USA). A future double-blind, randomized study of arketamine versus $(2 R, 6 R)-\mathrm{HNK}$ in MDD patients will be of great interest to confirm whether it is arketamine itself, or its metabolite, which contributes to antidepressant actions.

Taken together, it is unlikely that NMDAR inhibition plays a major role in the antidepressant effects of $(R, S)$ ketamine and its enantiomers in MDD patients [41-44, 90]. Nonetheless, a double-blind, randomized study of arketamine versus esketamine in MDD patients would be of great interest in confirming the role of NMDAR in the antidepressant action of $(R, S)$-ketamine.

\section{Ketamine-induced dissociation in humans}

NMDAR antagonists such as $(R, S)$-ketamine and phencyclidine (PCP) are well known to produce dissociation, such as an "out-of-body experience", in humans [91, 92]. It was previously suggested that dissociative symptoms caused by $(R, S)$-ketamine infusion might be associated with the antidepressant action in MDD patients [93]. However, Ballard and Zarate [94] recently reported that dissociation is not necessary for the antidepressant response to $(R, S)$-ketamine and a recent systematic review showed that the association between $(R, S)$-ketamine-induced dissociation and its antidepressant effects was inconsistent [95]. Intravenous administration of esketamine $(0.2$ and $0.4 \mathrm{mg} / \mathrm{kg})$ was also reported to produce dissociation in patients with treatmentresistant MDD [96]; in contrast, the incidence of dissociation after intravenous arketamine $(0.5 \mathrm{mg} / \mathrm{kg})$ administration in patients with treatment-resistant MDD is very low [87]. It is well accepted that NMDAR antagonists such as ketamine and PCP cause detrimental side effects, including psychosis and dissociation in humans in proportion to their potency at the NMDAR [97], and the difference in NMDAR potency between the two ketamine enantiomers may explain the divergence in their dissociative potential. Collectively, these studies indicate that it is unlikely that NMDAR plays a major role in the antidepressant actions of $(R, S)$-ketamine. Nonetheless, it will be of great interest to compare the antidepressant and dissociative effects of arketamine and esketamine in MDD patients [98].

\section{AMPAR activation}

\section{Ketamine and its two enantiomers}

It has been recognized that the rapid-acting antidepressantlike effects of $(R, S)$-ketamine are mediated through blockade of NMDARs located on $\gamma$-aminobutyric acid (GABA) ergic inhibitory interneurons, and that subsequent activation of the $\alpha$-amino-3-hydroxy-5-methyl-4-isoxazolepropionic acid receptor (AMPAR) is required for ketamine's antidepressant effects [99, 100]. Preclinical studies showed that pretreatment with the AMPAR antagonist 2,3-dihydroxy-6nitro-7-sulfamoylbenzo(F)quinoxaline (NBQX) could block the acute and sustained antidepressant-like effects of $(R, S)$ ketamine [101-103], and post treatment with NBQX reversed the effects of $(R, S)$-ketamine [104]. Furthermore, we reported that NBQX blocked the acute and sustained antidepressant-like effects of both arketamine and esketamine in a CSDS model [48]. Therefore, it appears likely that AMPAR activation may be necessary for rapid and sustained antidepressant-like effects of $(R, S)$-ketamine and its two constituent enantiomers [41-44, 105]. In order to confirm the role of AMPAR in the antidepressant actions of 
$(R, S)$-ketamine in humans, two clinical trials using AMPAR antagonist perampanel $\left(\right.$ Fycompa $\left.^{\circledR}\right)$ in patients with treatment-resistant MDD are underway at Yale University (NCT03367533) and the National Institute of Mental Health (NCT03973268).

\section{(S)-norketamine}

In contrast, we reported that AMPAR antagonists NBQX or 6-cyano-7-nitroquinoxaline-2,3-dione (CNQX) did not block the rapid-acting antidepressant-like effects of $(S)$ norketamine, the major metabolite of esketamine, in a CSDS model, nor did $(S)$-norketamine enhance AMPARmediated neurotransmission in hippocampal neurons [80]. Our data suggest that the metabolite $(S)$-norketamine exerts AMPAR-activation-independent antidepressant-like actions in rodents. Further study on the role of AMPAR activation in the antidepressant effects of $(R, S)$-ketamine and its metabolites is needed.

\section{Brain-derived neurotrophic factor and its receptor TrkB system}

\section{BDNF-TrkB system}

Multiple lines of evidence suggest that brain-derived neurotrophic factor (BDNF) and its receptor tropomyosin receptor kinase B (TrkB) play a crucial role in depression and in the therapeutic mechanisms of antidepressants [106-112]. In 2002, Shirayama et al. [113] reported in a rat LH model that a single bilateral infusion of BDNF into the hippocampal dentate gyrus produced rapid antidepressant-like effects that were sustained for at least 10 days, indicating a key role for BDNF in antidepressant mechanisms. Garcia et al. [114] reported that ketamine (10 and $15 \mathrm{mg} / \mathrm{kg}$ ) increased hippocampal BDNF, which may contribute to the antidepressant-like effect of BDNF in rats. However, neither acute nor chronic administration of ketamine altered hippocampal BDNF levels in rats exposed to stress [115].

In 2011, Autry et al. [116] demonstrated that $(R, S)$ ketamine did not cause antidepressant-like effects in inducible $B d n f$ knockout (KO) mice, suggesting that the rapid synthesis of BDNF is necessary for the antidepressant-like effects of $(R, S)$-ketamine. Pretreatment with the TrkB inhibitor ANA-12 in a CSDS model blocked the antidepressant-like effects of both arketamine and esketamine [48]. Furthermore, arketamine produced more potent beneficial effects than esketamine on ameliorating the reduced BDNF-TrkB signaling observed in the PFC and hippocampus of CSDS-susceptible mice [48]. Moreover, the regulation of astrocytic glutamate transporter 1 by TrkB signaling plays a role in the antidepressant-like effects of $(R, S)$-ketamine in a chronic unpredictable mild stress model [117]. We previously demonstrated that mice lacking the transcription factor $\mathrm{Nrf} 2$ ( $N r f 2-\mathrm{KO}$ mice) show a depression-like phenotype through decreased BDNF-TrkB signaling in the PFC and hippocampus [118]. Recently, we reported that arketamine showed rapid-acting and sustained antidepressant-like effects in Nrf2-KO mice through TrkB activation [119]. Taken together, these studies suggest that activation of the BDNF-TrkB cascade in the PFC and hippocampus might be implicated in the long-lasting antidepressant effects of $(R, S)$-ketamine and its enantiomers [41-44].

Using conditional $B d n f-\mathrm{KO}$ mice, Anderzhanova et al. [120] reported that injection of esketamine $(10 \mathrm{or} 50 \mathrm{mg} /$ $\mathrm{kg}$ ) stimulated extracellular levels of mature BDNF in the medial PFC, in an FK-506- binding protein 51-dependent manner. Therefore, it would be interesting to determine the levels of mature BDNF in the medial PFC after injection of arketamine. Furthermore, D-serine, an endogenous co-agonist at NMDAR, showed antidepressantlike effects in control rats through AMPAR activation and subsequently increased BDNF expression in rat hippocampus [121]. A recent gene-based genome-wide association study in Taiwan showed the predictive role of BDNF-TrkB signaling, glutamatergic signaling, and GABAergic signaling in the antidepressant actions of $(R, S)$-ketamine in patients with treatment-resistant $\mathrm{MDD}$ [122]. Although BDNF plays an important role in antidepressant-like effects of ketamine and its two enantiomers, the precise molecular mechanisms underlying ketamine's actions on BDNF-TrkB signaling remain poorly understood.

In 2021, Casarotto et al. [123] reported that all antidepressants (i.e., imipramine, fluoxetine, venlafaxine, moclobemide, $(R, S)$-ketamine, and esketamine) bind to the transmembrane domain of TrkB. Furthermore, the antidepressant candidate $(2 R, 6 R)-\mathrm{HNK}$, but not its enantiomer $(2 S, 6 S)-\mathrm{HNK}$, binds to the transmembrane domain of TrkB, although it should be noted that $(2 S, 6 S)$-HNK, but not $(2 R, 6 R)$-HNK, showed antidepressant-like effects in chronic corticosterone-treated mice [70]. Casarotto et al. concluded that the binding of all antidepressants, including $(R, S)$-ketamine, esketamine, and $(2 R, 6 R)-\mathrm{HNK}$, to the transmembrane domain of TrkB, is the common mechanism of antidepressant effects. However, there are several concerns regarding this paper. First, the effects of arketamine were not investigated in the same assays, despite arketamine showing more potent antidepressant-like effects than esketamine and $(2 R, 6 R)$-HNK in rodents. Second, only the forced swimming test was performed in $\operatorname{TrkB}^{\mathrm{WT}}$ and $\operatorname{TrkB}^{\mathrm{Y} 433 \mathrm{~F}}$ mice without a depression-like phenotype in order to investigate antidepressant-like actions. Further study using several behavioral tests and rodents with depression-like phenotypes is required to confirm the role of 
$\operatorname{TrkB}^{\mathrm{Y} 433 \mathrm{~F}}$ in antidepressant-like actions. In addition, the inhibition constant of $(R, S)$-ketamine for TrkB $(\mathrm{Ki}=12.30$ $\mu \mathrm{M})$ is less potent than that of esketamine $(\mathrm{Ki}=2.86 \mu \mathrm{M})$ and $(2 R, 6 R)-\mathrm{HNK}(\mathrm{Ki}=2.23 \mu \mathrm{M})$, which is inconsistent with their respective potencies for antidepressant-like effects in rodents. Finally, it is known that $(R, S)$-ketamine can elicit robust antidepressant actions in patients with treatment-resistant MDD or BD who did not respond adequately to two or more courses of other current antidepressants. Thus, the conclusion of the article by Casarotto et al. [123] is contradictory to the clinical evidence from $(R$, $S$ )-ketamine in patients with treatment-resistant MDD. Therefore, further detailed study is needed to confirm the hypothesis that binding to the TrkB transmembrane domain is a mechanism common to all antidepressants.

\section{Transforming growth factor $\beta 1$ (TGF- $\beta 1$ ) system}

As we have discussed here, arketamine has more potent antidepressant-like effects than esketamine in rodents; however, the precise molecular mechanisms underlying the differences between the two enantiomers remain unclear. Using RNA sequencing in the PFC of a CSDS model, we found that transforming growth factor $\beta 1$ (TGF- $\beta 1$ ) plays a role in the antidepressant-like effects of arketamine [124]. TGF- $\beta 1$ and its receptors are expressed in microglia, but not astrocytes, in the mouse PFC. Interestingly, partial depletion of microglia in the PFC by PLX3397, an inhibitor of colony-stimulating factor 1 receptor (CSF1R), blocked the antidepressant-like effects of arketamine in a CSDS model, suggesting a potential role for microglial TGF- $\beta 1$ in the antidepressant-like effects of arketamine [124]. Furthermore, intracerebroventricular injection of recombinant TGF- $\beta 1$ resulted in rapid and sustained antidepressant-like effects in a CSDS model [124]. Moreover, we found that intranasal administration of TGF- $\beta 1$ elicited rapid-acting and sustained antidepressant-like effects in a CSDS model, and that the TrkB antagonist ANA-12 blocked these TGF- $\beta 1$ effects [125], suggesting a role of TrkB signaling in the antidepressant-like effects of TGF- $\beta 1$.

Chronic stress has been shown to cause alterations in BDNF and TGF- $\beta 1$ levels in different brain regions of rodents [126-128]. Interestingly, Sometani et al. [129] reported that TGF- $\beta 1$ potentiated BDNF expression in cultured cerebral cortex neurons, partly via the neurotrophic activity of TGF- $\beta 1$. Interestingly, alterations in the TGF- $\beta 1$ system have been reported in MDD patients [130-133]. Given the evident interplay between the BDNF-TrkB and TGF- $\beta 1$ systems, we suggest that the BDNF-TrkB system plays a role in the rapid-acting antidepressant-like actions of TGF- $\beta 1$ (Fig. 2), and although further study of this interaction is needed, intranasal TGF- $\beta 1$ administration could be a novel therapeutic approach for depression.

\section{mTORC1, extracellular signal-regulated kinase, eEF2K, 4E-BPs, and neuregulin-1}

In 2010, Li et al. [102] demonstrated that rapamycin, a mechanistic target of rapamycin (mTOR) inhibitor, blocked the antidepressant-like effects of $(R, S)$-ketamine in rodents, implicating mTOR complex 1 (mTORC1) as a mediator of $(R, S)$-ketamine's antidepressant-like effects. It has been shown that mTORC1 plays a role in the antidepressant-like effects of esketamine, but may not play such a role for arketamine [51]. Rather, the antidepressant-like actions of arketamine may be mediated by extracellular signal-regulated kinase (ERK) activation (Fig. 2) [51]. Unexpectedly, pretreatment with rapamycin did not block, but rather prolonged, the antidepressant actions of $(R, S)$-ketamine $(0.5 \mathrm{mg} / \mathrm{kg})$ in patients with treatment-resistant MDD [134]. At present, studies into the role of mTORC1 in the antidepressant-like effects of $(R, S)$-ketamine and its enantiomers have produced inconsistent results [41-44]. Further study is needed to fully understand the role of mTORC1 signaling in the actions of $(R, S)$-ketamine and its enantiomers.

Eukaryotic elongation factor 2 kinase $(\mathrm{eEF} 2 \mathrm{~K})$ is a protein kinase that regulates the elongation stage of protein synthesis. Monteggia et al. [135] proposed that eEF2K plays a role in mediating the antidepressant-like effects of $(R, S)$-ketamine, which did not show antidepressant-like effects in Eef $2 k \mathrm{KO}$ mice; however, it is noted that these mice did not display a depression-like phenotype [136]. It is known that mTORC1 controls several functions through translational regulation by eukaryotic initiation factor 4E-binding proteins (4E-BPs). In 2021, Aguilar-Valles et al. [137] reported that 4E-BPs play a role in the antidepressant-like effects of $(R, S)$-ketamine and $(2 R, 6 R)-\mathrm{HNK}$, although they did not use mice with depression-like behaviors. Further studies in rodents with depression-like phenotypes are needed to ascertain the role of eEF2K and 4E-BPs in the antidepressant-like effects of $(R, S)$ ketamine and its metabolites.

Ketamine is known to modulate the excitatory and inhibitory balance in the PFC. The epidermal growth factor family member neuregulin-1 (NRG1) and its receptor ErbB4 play a role in the regulation of inhibitory neural circuits in the PFC [138]. A recent study showed that the rapid and sustained antidepressant-like effects of $(R, S)$-ketamine may be mediated through cortical disinhibition via PV-specific NRG1 signaling in the medial PFC [139]. Future studies using rodents with depressionlike phenotypes are also required to confirm the role of NRG1 in the antidepressant-like effects of $(R, S)$-ketamine and its enantiomers. 


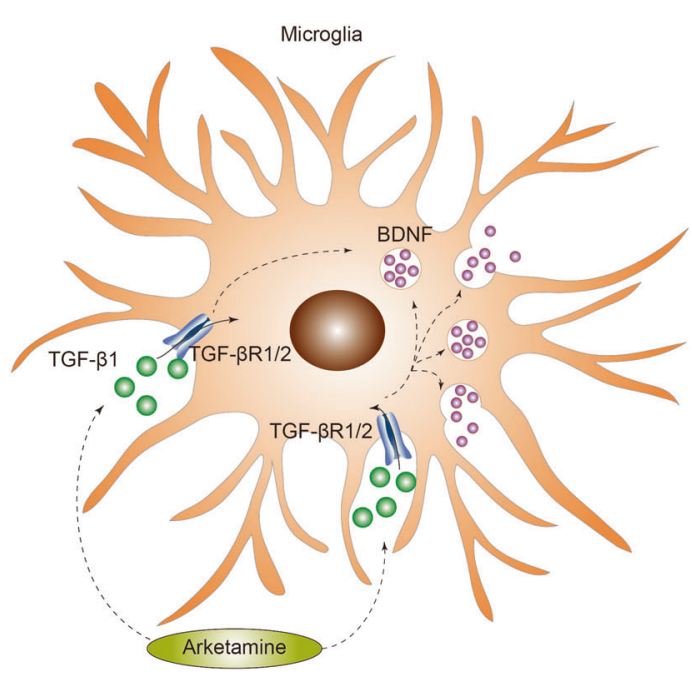

Fig. 2 Proposed signaling pathways underlying the antidepressantlike actions of arketamine and TGF- $\boldsymbol{\beta} 1$. Arketamine induces the expression of TGF- $\beta 1$ in the microglia through unidentified mechanisms. Arketamine-induced TGF- $\beta 1$ or TGF- $\beta 1$ bind to its receptor TGF- $\beta$ receptor $1 / 2$ in the microglia. Subsequently, released BDNF

\section{Brain-body crosstalk}

\section{Brain-gut-microbiota axis}

The gut microbiome and its associated short-chain fatty acids (SCFAs) play a role in the brain-gut-microbiota axis, which is involved in psychiatric and neurological disorders [140-145]. We reported that abnormalities in the composition of gut microbiota and SCFAs may contribute to resilience versus susceptibility in rodents exposed to stress [146-149]. Furthermore, the brain-gut-microbiota axis acts via the vagus nerve to play a key role in depression-like phenotypes in mice after transplantation of "depressionrelated microbes" $[150,151]$. Interestingly, $(R, S)$-ketamine and arketamine ameliorated the abnormal gut microbiota composition in mice with a depression-like phenotype [152-155]. Thus, the brain-gut-microbiota axis may, at least in part, play a role in antidepressant-like actions of $(R$, $S$ )-ketamine and arketamine, although further studies are needed to confirm the involvement of this axis [156].

\section{Brain-spleen axis}

The spleen is a large immune organ that plays a key role in the regulation of erythrocytes and the immune system. We recently reported an abnormality in the composition of mouse gut microbiota and SCFAs after splenectomy, suggesting a role for spleen in the brain-gut-microbiota axis [157]. CSDS-susceptible mice showed a larger spleen volume than in control (no CSDS) and CSDS-resilient mice[158]; interestingly, a single injection of arketamine could ameliorate the increased splenic weight in CSDS-susceptible mice [158].

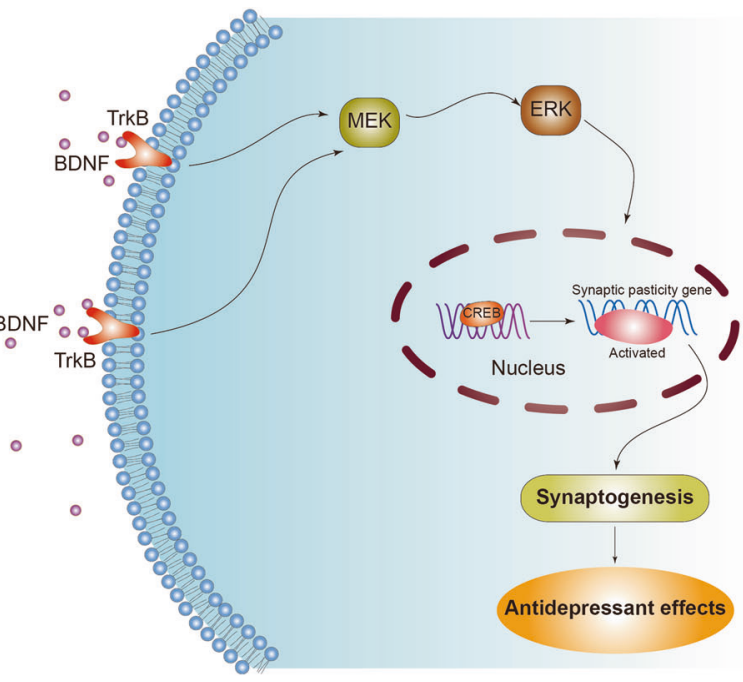

binds to its receptor TrkB, resulting in MEK-ERK-CREB signaling pathway, leading to synaptogenesis and antidepressant actions. MEK: mitogen-activated protein kinase, ERK: extracellular signal-regulated kinase, CREB: cAMP response element binding protein.

Depression-like behaviors, increased spleen volume, and abnormal composition of gut microbiota following injection of lipopolysaccharide (LPS) in mice were attenuated after subdiaphragmatic vagotomy, further suggesting a role of the brain-gut-microbiota axis via the vagus nerve [159]. Splenectomy prior to chronic sleep restriction abrogated the enhancement of LPS-induced increases in neuroinflammation and abnormal cognition and anxiety behaviors, implicating the spleen in sleep restriction-induced exacerbation of LPS-induced brain damage [160]. Moreover, stress-activated corticotropin-releasing hormone neurons control adaptive immunity in the spleen by direct innervation, suggesting a brain-spleen axis in the regulation of humoral immunity $[161,162]$. Collectively, it is likely that brain-spleen axis and brain-gut-microbiota axis via the vagus nerve play crucial roles in stress-related disorders (Fig. 3). In addition, using postmortem tissues, we reported correlations between BDNF propeptide in the brain and spleen [163], and a negative correlation between CSF1R and transcription factor PU.1 (SPI1) [164], suggesting a role for the brain-spleen axis in psychiatric disorders such as depression. It will be interesting to examine whether arketamine influences the observed abnormalities in the brain-spleen axis in stress-related psychiatric disorders (Fig. 3).

\section{Beyond depression}

\section{Cognitive impairments in psychiatric disorders}

Cognitive impairments have been shown in a range of psychiatric disorders, including schizophrenia, MDD, BD, PTSD, general anxiety disorder, obsessive compulsive disorder, 


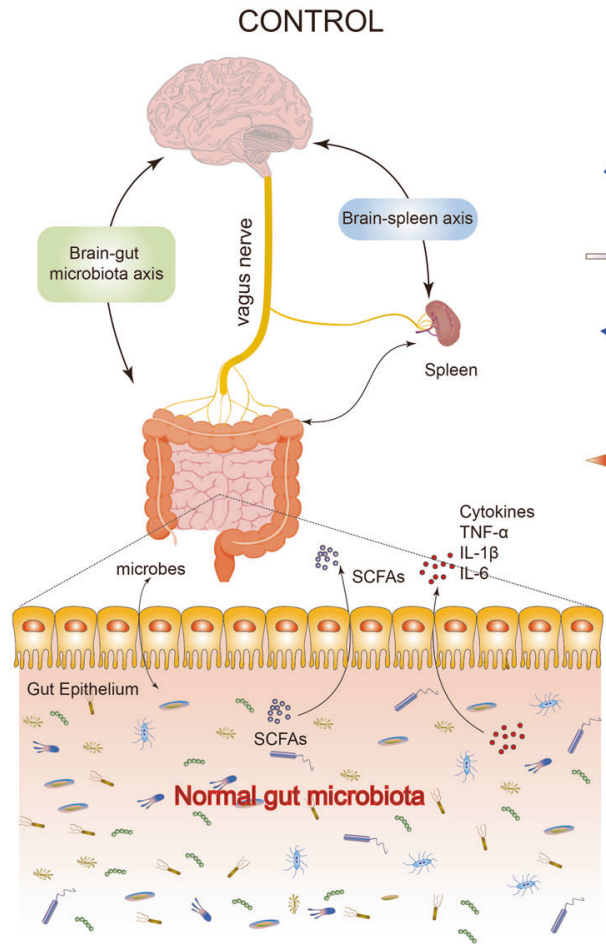

Fig. 3 Role of brain-gut-microbiota axis and brain-spleen axis in the stress-related psychiatric disorders and beneficial effects by arketamine. Repeated stress caused gut microbiota dysbiosis and an increase in spleen size and weight, resulting in abnormalities in immune system. Stress-induced neuroinflammation might be mediated by the brain-gut-microbiota axis and the brain-spleen axis through the

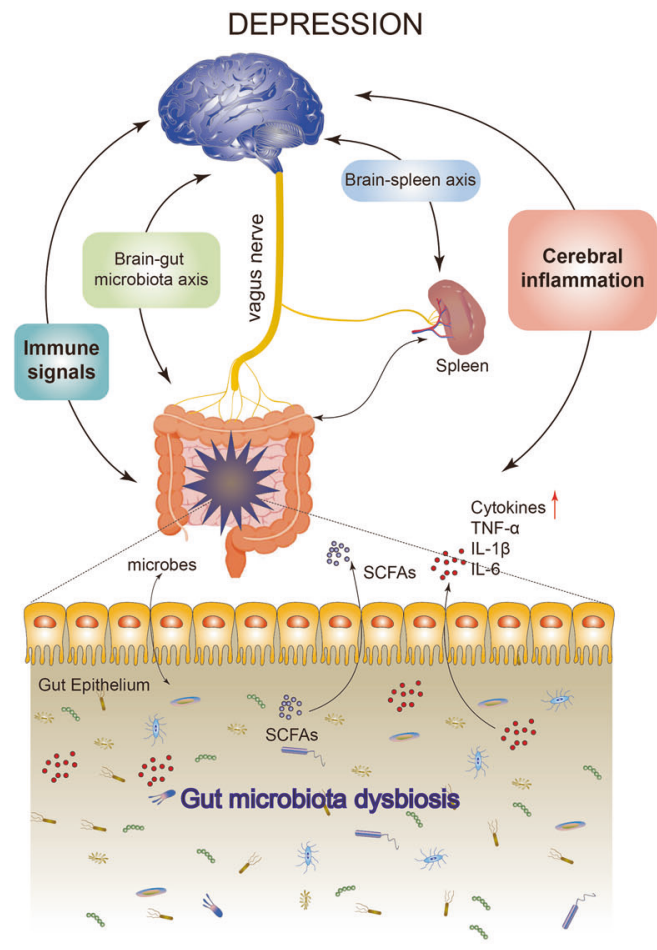

vagus nerve. Interestingly, arketamine could ameliorate the abnormalities of gut microbiota, abnormal functions of the spleen, and depressive symptoms in patients with stress-related disorders. A slight modification from the previous report [44]. Some materials of the figure have been designed using resources from Freepik.com.

worsen cognitive function in depressed patients [171], as had been observed in healthy controls [166, 167]. Furthermore, it was suggested that the improvement in working memory may be predictive of the anti-suicidal-ideation response to $(R, S)$-ketamine in patients with treatmentresistant MDD [172]. Thus, it is noteworthy that $(R, S)$ ketamine has beneficial effects on cognitive impairment in depressed patients.

In addition, we reported that PCP-induced cognitive deficits in mice were ameliorated after subsequent repeated intermittent administration of arketamine, but not esketamine, and that these effects were mediated by BDNF-TrkB activation [173]. As cognitive impairment can influence quality of life, it will be important to investigate whether arketamine can improve cognitive impairment in patients with psychiatric disorders (Fig. 4).

\section{Parkinson's disease}

Parkinson's disease (PD) is a chronic and progressive neurodegenerative disorder, in which depression is common [174]. In a mouse model of PD, 1-methyl-4-phenyl-1,2,3,6tetrahydropyridine (MPTP)-induced dopaminergic neurotoxicity in the mouse striatum was attenuated by treatment 
Fig. 4 Potential of arketamine for cognitive impairments in psychiatric disorders and other diseases. Preclinical findings suggest that arketamine would be a new therapeutic drug for cognitive impairments in psychiatric disorders, neurodegenerative disorders such as Parkinson's disease, osteoporosis, IBDs (ulcerative colitis and Crohn's disease), and stroke. Importantly, patients with these diseases have depressive symptoms as comorbidity. IBD is a risk factor for PD [180]. Some materials of the figure have been designed using resources from Freepik.com.

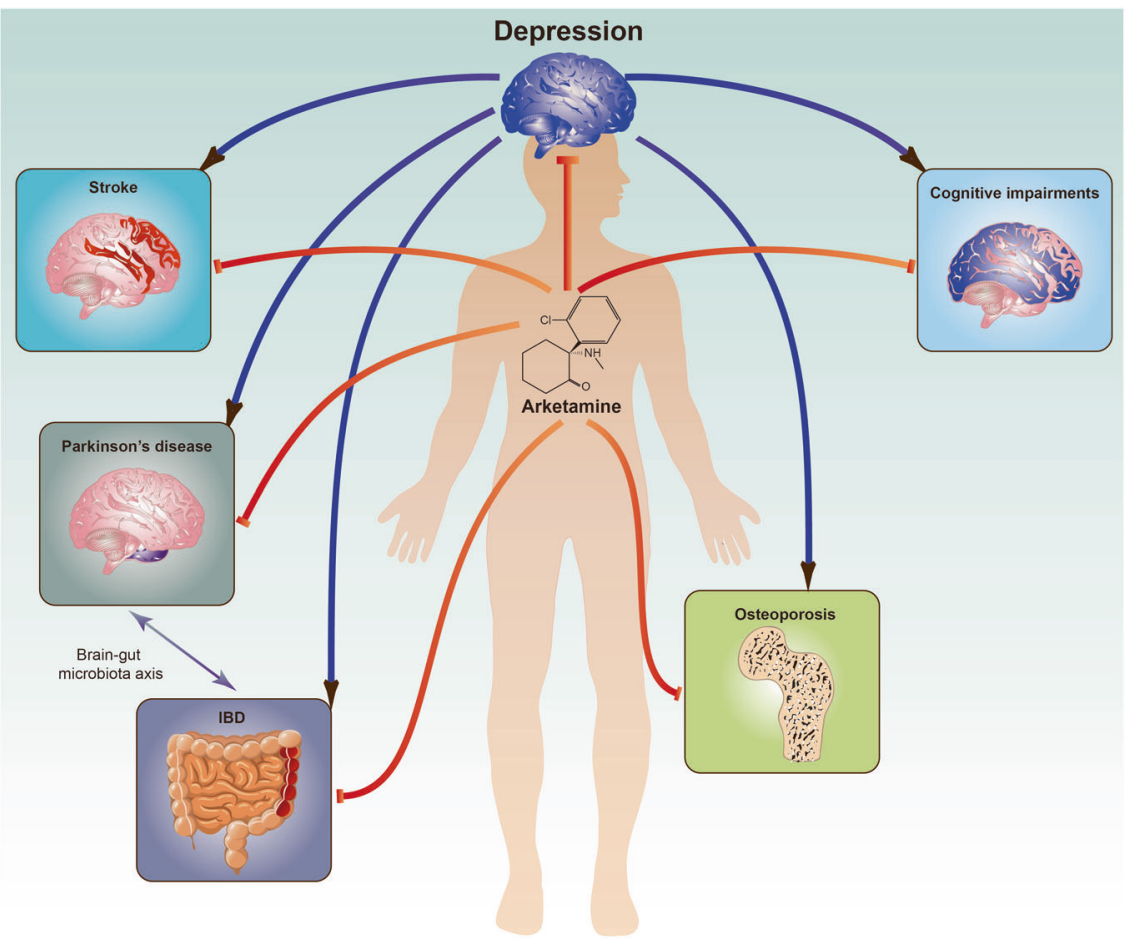

with repeated intranasal administration of arketamine, but not esketamine [175]. Furthermore, pretreatment with the TrkB inhibitor ANA-12 significantly blocked the beneficial effects of arketamine against MPTP neurotoxicity, suggesting that TrkB plays a role in the protective effects of arketamine. Therefore, arketamine could be a potential novel therapeutic for the treatment of neurodegenerative disorders such as PD (Fig. 4).

\section{Osteoporosis}

Depression is common in, and is a risk factor for, osteoporosis, particularly in women. Kadriu et al. [176] reported that bone inflammation markers might be involved in the antidepressant actions of $(R, S)$-ketamine in patients with treatment-resistant MDD. Arketamine, but not esketamine, significantly attenuated the increased plasma levels of receptor activator of nuclear factor $\mathrm{\kappa B}$ ligand (RANKL) observed in CSDS-susceptible mice [177]. Interestingly, there was a positive correlation between sucrose preference and ratio of osteoprotegerin (OPG) and RANKL [177]. Arketamine, but not $(2 R, 6 R)$-HNK, ameliorated the increased plasma levels of RANKL and decreased OPG/RANKL ratio found in CSDS-susceptible mice. Moreover, arketamine, but not its metabolite $(2 R, 6 R)$-HNK, ameliorated the decreased bone mineral density in CSDS-susceptible mice [178]. The decreased bone mineral density observed in ovariectomized mice was also ameliorated after subsequent repeated intermittent administration of arketamine, but not esketamine
[179]. These findings all suggest that arketamine could potentially be used as a therapeutic treatment for bone metabolism abnormalities in patients with MDD or osteoporosis (Fig. 4).

\section{Inflammatory bowel diseases}

Ulcerative colitis (UC) is a chronic inflammatory bowel disease (IBD) that causes long-lasting inflammation, ulcers, and colitis in the gastrointestinal tract. Depression is a common symptom in patients with UC, and is itself a risk factor for IBDs [180]. Accumulating evidence suggests that IBD might increase the risk of PD through the brain-gut-microbiota axis [181]. In a dextran sulfate sodium (DSS)-induced mouse model of colitis, repeated administration of arketamine, but not esketamine, significantly ameliorated the DSS-induced inflammation and colitis through TrkB activation [182]. These data suggest that arketamine could be a potential therapeutic drug for IBD (Fig. 4). Therefore, a further double-blind, placebo-controlled study of arketamine in IBD patients with or without depression would be of much interest.

\section{Stroke}

Stroke is the most common acute cerebrovascular disease. Importantly, poststroke depression occurs in a number of patients with stroke, leading to greater disability as well as increased mortality [183]. Brain injury and behavioral abnormalities in mice after middle cerebral artery occlusion 
(MCAO) were attenuated by subsequent administration ( 1 and $24 \mathrm{~h}$ after MCAO) of arketamine but not of esketamine [184]. This study suggests that arketamine may have potential as a new therapeutic drug for ischemic stroke and poststroke depression (Fig. 4).

\section{Conclusion}

Considering the preclinical findings in studies of the two ketamine enantiomers, and the inability of non-ketamine NMDAR compounds to replicate the effects of $(R, S)$-ketamine in MDD patients, it is unlikely that NMDAR plays a major role in the antidepressant effects of $(R, S)$-ketamine and arketamine. However, further study in this field is required. At present, the primary molecular mechanism by which arketamine exerts its antidepressant actions is unknown. Further study using new technologies such as chemical biology is needed to fully understand the molecular pathways of arketamine and identify novel targets for treatment intervention.

An open-label study of arketamine in patients with treatment-resistant MDD showed robust antidepressant actions [87]; these results must be confirmed in a randomized, placebo-controlled, double-blind study using a large sample size. A clinical trial of arketamine by Perception Neuroscience, Inc. (New York, USA) is underway. In February 19, 2021, Perception Neuroscience announced the positive data from the first Phase 1 study showing the safety and tolerability of arketamine [185]. Arketamine was safe and well-tolerated at all doses up to $150 \mathrm{mg}$. Furthermore, arketamine required substantially higher doses to induce similar perceptional changes than esketamine [185]. Phase 2 study of arketamine in patients with treatment-resistant depression will be started from the second quarter of 2021 .

A future randomized, double-blind study of arketamine versus esketamine [or $(2 R, 6 R)-\mathrm{HNK}$ ] in patients with treatment-resistant MDD is needed to ascertain the role of the NMDAR in the robust antidepressant actions of $(R, S)$ ketamine. Finally, we propose that arketamine could prove beneficial as a treatment for MDD, BD, PTSD, cognitive impairment in psychiatric disorders, PD, osteoporosis, IBD, and stroke.

Acknowledgements We would like to thank our collaborators who are listed as the coauthors of our papers in the reference list. This study was supported by grant from Japan Agency for Medical Research and Development (AMED) (to KH, JP20dm0107119) and the National Natural Science Foundation of China (NSFC) (to YW, 31701009).

\section{Compliance with ethical standards}

Conflict of interest $\mathrm{KH}$ is the inventor of filed patent applications on "The use of $R$-ketamine in the treatment of psychiatric diseases",
"(S)-norketamine and salt thereof as pharmaceutical", " $R$-ketamine and derivative thereof as prophylactic or therapeutic agent for neurodegeneration disease or recognition function disorder", "Preventive or therapeutic agent and pharmaceutical composition for inflammatory diseases or bone diseases", " $R$-ketamine and its derivatives as a preventive or therapeutic agent for a neurodevelopmental disorder", and "TGF- $\beta 1$ in the treatment of depression" by the Chiba University. KH also declares that he has received research support and consultant from Dainippon Sumitomo, Otsuka, and Taisho. The other authors have no conflict of interest.

Publisher's note Springer Nature remains neutral with regard to jurisdictional claims in published maps and institutional affiliations.

Open Access This article is licensed under a Creative Commons Attribution 4.0 International License, which permits use, sharing, adaptation, distribution and reproduction in any medium or format, as long as you give appropriate credit to the original author(s) and the source, provide a link to the Creative Commons license, and indicate if changes were made. The images or other third party material in this article are included in the article's Creative Commons license, unless indicated otherwise in a credit line to the material. If material is not included in the article's Creative Commons license and your intended use is not permitted by statutory regulation or exceeds the permitted use, you will need to obtain permission directly from the copyright holder. To view a copy of this license, visit http://creativecommons. org/licenses/by/4.0/.

\section{References}

1. Friedrich MJ. Depression is the leading cause of disability around the world. JAMA. 2017;317:1517.

2. Diseases GBD, Injuries C. Global burden of 369 diseases and injuries in 204 countries and territories, 1990-2019: a systematic analysis for the global burden of disease study 2019. Lancet. 2020;396:1204-22.

3. Can NO, Can OD, Osmaniye D, Demir Ozkay U. Synthesis of some novel thiadiazole derivative compounds and screening their antidepressant-like activities. Molecules. 2018;23:716.

4. Kato M, Hori $\mathrm{H}$, Inoue $\mathrm{T}$, Iga $\mathrm{J}$, Iwata $\mathrm{M}$, Inagaki $\mathrm{T}$, et al. Discontinuation of antidepressants after remission with antidepressant medication in major depressive disorder: a systematic review and meta-analysis. Mol Psychiatry. 2021;26:118-33.

5. Hashimoto K, Sawa A, Iyo M. Increased levels of glutamate in brains from patients from mood disorders. Biol Psychiatry. 2007;62:1310-6.

6. Sanacora G, Zarate CA Jr, Krystal JH, Manji HK. Targeting the glutamatergic system to develop novel, improved therapeutics for mood disorders. Nat Rev Drug Disco. 2008;7:426-37.

7. Hashimoto K. Emerging role of glutamate in the pathophysiology of major depressive disorder. Brain Res Rev. 2009;61:105-23.

8. Vollenweider FX, Kometer M. The neurobiology of psychedelic drugs: implications for the treatment of mood disorders. Nat Rev Neurosci. 2010;11:642-51.

9. Tokita K, Yamaji T, Hashimoto K. Roles of glutamate signaling in preclinical and/or mechanistic models of depression. Pharm Biochem Behav. 2012;100:688-704.

10. Hashimoto K, Malchow B, Falkai P, Schmitt A. Glutamate modulators as potential therapeutic drugs in schizophrenia and affective disorders. Eur Arch Psychiatry Clin Neurosci. 2013;263:367-77.

11. Dang YH, Ma X, Zhang JC, Ren Q, Wu J, Gao CG, et al. Targeting of NMDA receptors in the treatment of major depression. Curr Pharm Des. 2014;20:5151-9. 
12. Ohgi Y, Futamura T, Hashimoto K. Glutamate signaling in synaptogenesis and NMDA receptors as potential therapeutic targets for psychiatric disorders. Curr Mol Med. 2015;15: 206-21.

13. Hashimoto K, Bruno D, Nierenberg J, Marmar CR, Zetterberg H, Blennow K, et al. Abnormalities in glutamine-glutamate cycle in the cerebrospinal fluid of cognitively intact elderly individuals with major depressive disorder: a 3-year follow-up study. Trans1 Psychiatry. 2016;6:e744.

14. Murrough JW, Abdallah CG, Mathew SJ. Targeting glutamate signaling in depression: progress and prospects. Nat Rev Drug Disco. 2017;16:472-86.

15. Li CT, Yang KC, Lin WC. Glutamatergic dysfunction and glutamatergic compounds for major psychiatric disorders: evidence from clinical neuroimaging studies. Front Psychiatry. 2018;9:767.

16. Duman RS. Ketamine and rapid-acting antidepressants: a new era in the battle against depression and suicide. F1000Res 2018;7:659.

17. Krystal JH, Abdallah CG, Sanacora G, Charney DS, Duman RS. Ketamine: A paradigm shift for depression research and treatment. Neuron. 2019;101:774-8.

18. Zhang K, Hashimoto K. An update on ketamine and its two enantiomers as rapid-acting antidepressants. Expert Rev Neurother. 2019;19:83-92.

19. Berman RM, Cappiello A, Anand A, Oren DA, Heninger GR, Charney DS, et al. Antidepressant effects of ketamine in depressed patients. Biol Psychiatry. 2000;47:351-4.

20. Zarate CA Jr., Singh JB, Carlson PJ, Brutsche NE, Ameli R, Luckenbaugh DA, et al. A randomized trial of an $N$-methyl-Daspartate antagonist in treatment-resistant major depression. Arch Gen Psychiatry. 2006;63:856-64.

21. Diazgranados N, Ibrahim L, Brutsche NE, Newberg A, Kronstein $\mathrm{P}$, Khalife $\mathrm{S}$, et al. A randomized add-on trial of an $\mathrm{N}$-methyl-Daspartate antagonist in treatment-resistant bipolar depression. Arch Gen Psychiatry. 2010;67:793-802.

22. Zarate CA Jr, Brutsche NE, Ibrahim L, Franco-Chaves J, Diazgranados N, Cravchik A, et al. Replication of ketamine's antidepressant efficacy in bipolar depression: a randomized controlled add-on trial. Biol Psychiatry. 2012;71:939-46.

23. Murrough JW, Soleimani L, DeWilde KE, Collins KA, Lapidus KA, Iacoviello BM, et al. Ketamine for rapid reduction of sucidal ideation: a randomized controlled trial. Psychol Med. 2015;45: 3571-80.

24. Newport DJ, Carpenter LL, McDonald WM, Potash JB, Tohen $\mathrm{M}$, Nemeroff $\mathrm{CB}$, et al. Ketamine and other NMDA antagonists: early clinical trials and possible mechanisms in depression. Am J Psychiatry. 2015;172:950-66.

25. Kishimoto T, Chawla JM, Hagi K, Zarate CA Jr, Kane JM, Bauer M, et al. Single-dose infusion ketamine and non-ketamine $N$-methyl-D-aspartate receptor antagonists for unipolar and bipolar depression: a meta-analysis of efficacy, safety and time trajectories. Psychol Med. 2016;46:1459-72.

26. Su TP, Chen MH, Li CT, Lin WC, Hong CJ, Gueorguieva R, et al. Dose-related effects of adjunctive ketamine in Taiwanese patients with treatment-resistant depression. Neuropsychopharmacology. 2017;42:2482-92.

27. Wilkinson ST, Ballard ED, Bloch MH, Mathew SJ, Murrough JW, Feder A, et al. The effect of a single dose of intravenous ketamine on suicidal ideation: a systematic review and individual participant data meta-analysis. Am J Psychiatry. 2018;175:150-8.

28. Zheng W, Zhou YL, Liu WJ, Wang CY, Zhan YN, Li HQ, et al. Rapid and longer-term antidepressant effects of repeated-dose intravenous ketamine for patients with unipolar and bipolar depression. Psychiatry Res. 2018;106:61-68.

29. Feder A, Parides MK, Murrough JW, Perez AM, Morgan JE, Saxena $\mathrm{S}$, et al. Efficacy of intravenous ketamine for treatment of chronic posttraumatic stress disorder: a randomized clinical trial. JAMA Psychiatry. 2014;71:681-8.

30. Feder A, Costi S, Rutter SB, Collins AB, Govindarajulu U, Jha $\mathrm{MK}$, et al. A randomized controlled trial of repeated ketamine administration for chronic posttraumatic stress disorder. Am J Psychiatry. 2021;178:193-202.

31. Sanacora G, Frye MA, McDonald W, Mathew SJ, Turner MS, Schatzberg AF, et al. A consensus statement on the use of ketamine in the treatment of mood disorders. JAMA Psychiatry. 2017;74:399-405.

32. Wilkinson ST, Sanacora G. Considerations on the off-label use of ketamine as a treatmnent for mood disorders. JAMA. 2017; 318:793-4.

33. López-Díaz Á, Murillo-Izquierdo M, Moreno-Mellado E. Off-label use of ketamine for treatment-resistant depression in clinical practice: European perspective. Br J Psychiatry. 2019;215:447-8.

34. Kim J, Farchinose T, Potter A, Chen Q, Temple R. Esketamine for treatment-resistant depression-first FDA-approved antidepressant in a new class. N. Engl J Med. 2019;381:1-4.

35. Mahase E. Esketamine is approved in Europe for treating resistant major depressive disorder. BMJ. 2019;367:17069.

36. Turner E. Esketamine for treatment-resistant depression: seven concerns about efficacy and FDA approval. Lancet Psychiatry. 2019;6:977-9.

37. Horowitz MA, Moncrieff $\mathbf{J}$ Are we repeating mistakes of the past? A review of the evidence for esketamine. Br J Psychiatry. 2020:1-4. https://doi.org/10.1192/bjp.2020.89.

38. Hashimoto K. The $R$-enantiomer of ketamine as an alternative for ketamine for treatment-resistant major depression. Clin Psychopharmacol Neurosci. 2014;12:72-73.

39. Hashimoto K. R-ketamine: a rapid-onset and sustained antidepressant without risk of brain toxicity. Psychol Med. 2016; 46:2449-51.

40. Hashimoto K. Detrimental side effects of repeated ketamine infusions in the brain. Am J Psychiatry. 2016;173:1044-5.

41. Hashimoto K. Rapid-acting antidepressant ketamine, its metabolites and other candidates: a historical overview and future perspective. Psychiatry Clin Neurosci. 2019;73:613-27.

42. Yang C, Yang J, Luo A, Hashimoto K. Molecular and cellular mechanisms underlying the antidepressant effects of ketamine enantiomers and its metabolites. Transl Psychiatry. 2019;9:280.

43. Wei Y, Chang L, Hashimoto K. A historical review of antidepressant effects of ketamine and its enantiomers. Pharm Biochem Behav. 2020;190:172870.

44. Hashimoto K. Molecular mechanisms of the rapid-acting and long-lasting antidepressant actions of $(R)$-ketamine. Biochem Pharm. 2020;177:113935.

45. Sofia RD, Harakal JJ. Evaluation of ketamine $\mathrm{HCl}$ for antidepressant activity. Arch Int Pharmacodyn Ther. 1975;214:68-74.

46. Ebert B, Mikkelsen S, Thorkildsen C, Borgbjerg FM. Norketamine, the main metabolite of ketamine, is a non-competitive NMDA receptor antagonist in the rat cortex and spinal cord. Eur J Pharm. 1997;333:99-104.

47. Zhang JC, Li SX, Hashimoto K. $R$ (-)-ketamine shows greater potency and longer lasting antidepressant effects than $S$ (+)-ketamine. Pharm Biochem Behav. 2014;116:137-41.

48. Yang C, Shirayama Y, Zhang JC, Ren Q, Yao W, Ma M, et al. $R$ ketamine: a rapid-onset and sustained antidepressant without psychotomimetic side effects. Transl Psychiatry. 2015;5:e632.

49. Zanos P, Moaddel R, Morris PJ, Georgiou P, Fischell J, Elmer GI, et al. NMDAR inhibition-independent antidepressant actions of ketamine metabolites. Nature. 2016;533:481-6.

50. Fukumoto K, Toki H, Iijima M, Hashihayata T, Yamaguchi JI, Hashimoto $\mathrm{K}$, et al. Antidepressant potential of $(R)$-ketamine in rodent models: comparison with $(S)$-ketamine. J Pharm Exp Ther. 2017;361:9-16. 
51. Yang C, Ren Q, Qu Y, Zhang JC, Ma M, Dong C, et al. Mechanistic target of rapamycin-independent antidepressant effects of $(R)$-ketamine in a social defeat stress model. Biol Psychiatry. 2018;83:18-28.

52. Chang L, Zhang K, Pu Y, Qu Y, Wang SM, Xiong Z, et al. Comparison of antidepressant and side effects in mice after intranasal administration of $(R, S)$-ketamine, $(R)$-ketamine, and $(S)$-ketamine. Pharm Biochem Behav. 2019;181:53-59.

53. Zhu J, Hawkins E, Phillips K, Deshpande LS. Assessment of ketamine and its enantiomers in an organophosphate-based rat model for features of Gulf War illness. Int J Environ Res Public Health. 2020;17:4710.

54. Yang C, Han M, Zhang JC, Ren Q, Hashimoto K. Loss of parvalbumin-immunoreactivity in mouse brain regions after repeated intermittent administration of esketamine, but not $R$ ketamine. Psychiatry Res. 2016;239:281-3.

55. Tan Y, Hashimoto K. Risk of psychosis after repeated intermittent administration of $(S)$-ketamine, but not $(R)$-ketamine, in mice. J Affect Disord. 2020;269:198-200.

56. Hashimoto K, Kakiuchi T, Ohba H, Nishiyama S, Tsukada H. Reduction of dopamine $\mathrm{D}_{2 / 3}$ receptor binding in the striatum after a single administration of esketamine, but not $R$-ketamine: A PET study in conscious monkeys. Eur Arch Psychiatry Clin Neurosci. 2017;267:173-6.

57. Zanos P, Moaddel R, Morris PJ, Riggs LM, Highland JN, Georgiou P, et al. Ketamine and ketamine metabolites pharmacology: insights into therapeutic mechanisms. Pharm Rev. 2018;70:621-60.

58. Masaki Y, Kashiwagi Y, Watabe H, Abe K. (R)- and (S)-ketamine induce differential fMRI responses in conscious rats. Synapse. 2019;73:e22126.

59. Vollenweider FX, Leenders KL, Oye I, Hell D, Angst J. Differential psychopathology and patterns of cerebral glucose utilisation produced by $(S)$ - and $(R)$-ketamine in healthy volunteers using positron emission tomography (PET). Eur Neuropsychopharmacol. 1997;7:25-38.

60. Wray NH, Schappi JM, Singh H, Senese NB, Rosenick MM. NMDAR-independent, cAMP-dependent antidepressant actions of ketamine. Mol Psychiatry. 2019;24:1833-43.

61. Mion G, Villevieille T. Ketamine pharmacology: an update (pharmacocodynamic and molecular aspects, recent findings). CNS Neurosci Ther. 2013;19:370-80.

62. Singh NS, Zarate CA Jr, Moaddel R, Bernier M, Wainer IW. What is hydroxynorketamine and what can it bring to neurotherapeutics? Expert Rev Neurother. 2014;14:1239-42.

63. Zhang $\mathrm{K}$, Hashimoto $\mathrm{K}(R)$-ketamine: a new rapid-acting antidepressant. In "New Rapid-Acting Antidepressants" edited by K Hashimoto and M Manto. Springer Nature Publishing, 2021. In press.

64. Yang C, Qu Y, Abe M, Nozawa D, Chaki S, Hashimoto K. (R)ketamine shows greater potency and longer lasting antidepressant effects than its metabolite $(2 R, 6 R)$-hydroxynorketamine. Biol Psychiatry. 2017;82:e43-e44.

65. Shirayama Y, Hashimoto K. Lack of antidepressant effects of $(2 R, 6 R)$-hydroxynorketamine in a rat learned helplessness model: comparison with $(R)$-ketamine. Int $\mathrm{J}$ Neuropsychopharmacol. 2018;21:84-88.

66. Zhang K, Fujita Y, Hashimoto K. Lack of metabolism in $(R)$ ketamine's antidepressant actions in a chronic social defeat stress model. Sci Rep. 2018;8:4007.

67. Zhang K, Toki H, Fujita Y, Ma M, Chang L, Qu Y, et al. Lack of deuterium isotope effects in the antidepressant effects of $(R)$ ketamine in a chronic social defeat stress model. Psychopharmacol. 2018;235:3177-85.

68. Yamaguchi JI, Toki H, Qu Y, Yang C, Koike H, Hashimoto K, et al. $(2 R, 6 R)$-hydroxynorketamine is not essential for the antidepressant actions of $(R)$-ketamine in mice. Neuropsychopharmacology. 2018;43:1900-7.

69. Shirayama Y, Hashimoto K. Effects of a single bilateral infusion of $R$-ketamine in the rat brain regions of a learned helplessness model of depression. Eur Arch Psychiatry Clin Neurosci. 2017;267:177-82.

70. Yokoyama R, Higuchi M, Tanabe W, Tsukada S, Naito M, Yamaguchi T, et al. (S)-norketamine and $(2 S, 6 S)$-hydroxynorketamine exert potent antidepressant-like effects in a chronic corticosterone-induced mouse model of depression. Pharm Biochem Behav. 2020;191:172876.

71. Chaki S, Yamaguchi JI Chapter 37. (2R,6R)-hydroxynorkatamine as a novel antidepressant and its role in the antidepressant actions of $(R, S)$-ketamine. In "The Neuroscience of Depression: Features, Diagnosis and Treatment", edited by $\mathrm{C}$ Martin, LA Hunter, VR Preedy, V Patel, and R Rajendram. Elsevier Publishing, 2021. pp. 381-391.

72. Hashimoto K. Ketamine's antidepressant action: beyond NMDA receptor inhibition. Expert Opin Ther targets. 2016;20:1389-92.

73. Hashimoto K Rapid antidepressant activity of ketamine beyond NMDA receptor. In "The NMDA Receptors", edited by Kenji Hashimoto. Humana Press, 2017; pp.69-81.

74. Chaki S, Yamaguchi JI. Is the history repeated? Can $(2 R, 6 R)-$ hydroxynorkatamine be another antidepressant? J Exp Neurosci. 2018;12:1179069518815445.

75. Chou D, Peng HY, Lin TB, Lai CY, Hsieh MC, Wen YC. et al. (2R,6R)-hydroxynorketamine rescues chronic stress-induced depression-like behavior through its actions in the midbrain periaqueductal gray. Neuropharmacology.2018;139:1-12.

76. Pham TH, Defaix C, Xu X, Deng SX, Fabresse N, Alvarez JC, et al. Common neurotransmission recruited in $(R, S)$-ketamine and $(2 R, 6 R)$-hydroxynorketamine-induced sustaind antidepressant-like effects. Biol Psychiatry. 2018;84:e3-e6.

77. Fukumoto K, Fogaça MV, Liu RJ, Duman C, Kato T, Li XY, et al. Activity-dependent brain-derived neurotrophic factor signaling is required for the antidepressant actions of $(2 R, 6 R)$ hydroxynorketamine. Proc Natl Acad Sci USA. 2019;116: 297-302.

78. Nugent AC, Ballard ED, Gould TD, Park LT, Moaddel R, Brutsche NE, et al. Ketamine has distinct electrophysiological and behavioral effects in depressed and healthy subjects. Mol Psychiatry. 2019;24:1040-52.

79. Hashimoto K, Shirayama Y. What are the causes for discrepancies of antidepressant actions of $(2 R, 6 R)$-hydroxynorketamine? Biol Psychiatry. 2018;84:e7-e8.

80. Yang C, Kobayashi S, Nakao K, Dong C, Han M, Qu Y, et al. AMPA receptor activation-independent antidepressant actions of ketamine metabolite $(S)$-norketamine. Biol Psychiatry. 2018;84: 591-600.

81. Hashimoto K, Yang C. Is $(S)$-norketamine an alternative antidepressant for esketamine? Eur Arch Psychiatry Clin Neurosci. 2019;269:867-8.

82. Harmer CJ, Duman RS, Cowen PJ. How do antidepressants work? New perspectives for refining future treatment approaches. Lancet Psychiatry. 2017;4:409-18.

83. Yang B, Ren Q, Ma M, Chen QX, Hashimoto K. Antidepressant effects of (+)-MK-801 and (-)-MK-801 in the social defeat stress model. Int J Neuropsychopharmacol. 2016;19:pyw080.

84. Reardon S. Depression researchers rethink mouse swim test. Nature. 2019;571:456-7.

85. Bahji A, Vazquez GH, Zarate CA Jr. Comparative efficacy of racemic ketamine and esketamine for depression: A systematic review and meta-analysis. J Affect Disord. 2021;278:542-55.

86. Correia-Melo FS, Leal GC, Vieira F, Jesus-Nunes AP, Mello RP, Magnavita G, et al. Efficacy and safety of adjunctive therapy using esketamine or racemic ketamine for adult treatment- 
resistant depression: A randomized, double-blind, non-inferiority study. J Affect Disord. 2020;264:527-34.

87. Leal GC, Bandeira ID, Correia-Melo FS, Telles M, Mello RP, Vieira F, et al. Intravenous arketamine for treatment-resistant depression: open-label pilot study. Eur arch psychiatry clin neurosci. 2021;271:577-82.

88. Farmer CA, Gilbert JR, Moaddel R, George J, Adeojo L, Lovett $\mathrm{J}$, et al. Ketamine metabolites, clinical response, and gamma power in a randomized, placebo-controlled, crossover trial for treatment-resistant major depression. Neuropsychopharmacology. 2020;45:1398-404.

89. Abdallah CG. (2R,6R)-hydroxynorketamine (HNK) plasma level predicts poor antidepressant response: is this the end of the HNK pipeline?. Neuropsychopharmacology. 2020;45:1245-6.

90. Hashimoto K. Are NMDA and opioid receptors involved in the antidepressant actions of ketamine? Proc Natl Acad Sci USA. 2020;117:11200-1.

91. Domino EF. Taming the ketamine tiger. 1965. Anesthesiology. 2010;113:678-84.

92. Domino EF, Luby ED. Phencyclidine/schizophrenia: one view toward the past, the other to the future. Schizophr Bull. 2012;38: 914-9.

93. Luckenbaugh DA, Niciu MJ, Ionescu DF, Nolan NM, Richards EM, Brutsche NE, et al. Do the dissociative side effects of ketamine mediate its antidepressant effects? J affect disord. 2014;159:56-61.

94. Ballard ED, Zarate CA Jr. The role of dissociation in ketamine's antidepressant effects. Nat Commun. 2020;11:6431.

95. Mathai DS, Meyer MJ, Storch EA, Kosten TR. The relationship between subjective effects induced by a single dose of ketamine and treatment response in patients with major depressive disorder: a systematic review. J affect disord. 2020;264:123-9.

96. Singh JB, Fedgchin M, Daly E, Xi L, Melman C, De Bruecker G, et al. Intravenous esketamine in adult treatment-resistant depression: a double-blind, double-randomization, placebocontrolled study. Biol Psychiatry. 2016;80:424-31.

97. Javitt DC, Zukin SR. Recent advances in the phencyclidine model of schizophrenia. Am J Psychiatry. 1991;148:1301-8.

98. Hashimoto K. Neural rhythm in the retrosplenial cortex during ketamine-induced dissociation. Eur Arch Psychiatry Clin Neurosci. 2021;271:583-5.

99. Duman RS, Sanacora G, Krystal JH. Altered connectivity in depression: GABA and glutamate neurotransmitter deficits and reversal by novel treatments. Neuron. 2019;102:75-90.

100. Gould T, Zarate CA Jr, Rhompson SM. Molecular pharmacology and neurobiology of rapid-acting antidepressants. Anun Rev Pharm Toxicol. 2019;59:213-36.

101. Maeng S, Zarate CA Jr, Du J, Schloesser RJ, McCammon J, Chen G, et al. Cellular mechanisms underlying the antidepressant effects of ketamine: role of alpha-amino-3-hydroxy5-methylisoxazole-4-propionic acid receptors. Biol Psychiatry. 2008;63:349-52.

102. Li N, Lee B, Liu RJ, Banasr M, Dwyer JM, Iwata M, et al. mTORdependent synapse formation underlies the rapid antidepressant effects of NMDA antagonists. Science. 2010;329:959-64.

103. Koike H, Iijima M, Chaki S. Involvement of AMPA receptor in both the rapid and sustained antidepressant-like effects of ketamine in animal models of depression. Behav Brain Res. 2011; 224:107-11.

104. Koike H, Chaki S. Requirement of AMPA receptor stimulation for the sustained antidepressant activity of ketamine and LY341495 during the forced swim test in rats. Behav Brain Res. 2014;271:111-5.

105. Jelen LA, Young AH, Stone JM. Ketamine: a tale of two enantiomers. J Psychopharmacol. 2021;35:109-23.
106. Nestler E, Barrot M, DiLeone RJ, Eisch AJ, Gold SJ, Monteggia LM. Neurobiology of depression. Neuron. 2002;34:13-25.

107. Hashimoto K, Shimizu E, Iyo M. Critical role of brain-derived neurotrophic factor in mood disorder. Brain Res Rev. 2004;45: 104-14.

108. Hashimoto K. Brain-derived neurotrophic factor as a biomarker for mood disorders: an historical overview and future directions. Psychiatry Clin Neurosci. 2010;64:341-57.

109. Castrén E, Rantamäki T. The role of BDNF and its receptors in depression and antidepressant drug action: reactivation of developmental plasticity. Dev Neurobiol. 2010;70:289-97.

110. Hashimoto K. Sigma-1 receptor chaperone and brain-derived neurotrophic factor: emerging links between cardiovascular disease and depression. Prog Neurobiol. 2013;100:15-29.

111. Björkholm C, Monteggia LM. BDNF-a key transducer of antidepressant effects. Neuropharmacology. 2016;102:72-79.

112. Zhang JC, Yao W, Hashimoto K. Brain-derived neurotrophic factor (BDNF)-TrkB signaling in inflammation-related depression and potential therapeutic targets. Curr Neuropharmacol. 2016;14:721-31.

113. Shirayama Y, Chen ACH, Nakagawa S, Russell DS, Duman RS. Brain-derived neurotrophic factor produces antidepressant effects in behavioral models of depression. J Neurosci. 2002;22:3251-61.

114. Garcia LS, Comim CM, Valvassori SS, Réus GZ, Barbosa LM, Andreazza AC, et al. Acute administration of ketamine induces antidepressant-like effects in the forced swimming test and increases BDNF levels in the rat hippocampus. Prog Neuropsychopharmacol Biol Psychiatry. 2008;32:140-4.

115. Garcia LS, Comim CM, Valvassori SS, Réus GZ, Stertz L, Kapczinski F, et al. Ketamine treatment reverses behavioral and physiological alterations induced by chronic mild stress in rats. Prog Neuropsychopharmacol Biol Psychiatry. 2009;33:450-5.

116. Autry AE, Adachi M, Nosyreva E, Na ES, Los MF, Cheng PF, et al. NMDA receptor blockade at rest triggers rapid behavioural antidepressant responses. Nature. 2011;475:91-95.

117. Liu WX, Wang J, Xie ZM, Xu N, Zhang GF, Jia M, et al. Regulation of glutamate transporter 1 via BDNF-TrkB signaling plays a role in the anti-apoptotic and antidepressant effects of ketamine in chronic unpredictable stress model of depression. Psychopharmacol. 2016;233:405-15.

118. Yao W, Zhang JC, Ishima T, Dong C, Yang C, Ren Q, et al. Role of Keap1-Nrf2 signaling in depression and dietary intake of glucoraphanin confers stress resilience in mice. Sci Rep. 2016;6:30659.

119. Qu Y, Shan J, Wang S, Chang L, Pu Y, Wang X, et al. Rapidacting and long-lasting antidepressant-like action of $(R)$-ketamine in Nrf2 knock-out mice: a role of TrkB signaling. Eur Arch Psychiatry Clin Neurosci. 2021;271:439-46.

120. Anderzhanova E, Hafner K, Genewsky AJ, Soliman A, Pöhlmann ML, Schmidt MV, et al. The stress susceptibility factor FKBP51 controls $S$-ketamine-evoked release of mBDNF in the prefrontal cortex of mice. Neurobiol Stress. 2020;13:100239.

121. Wei IH, Chen KT, Tsai MH, Wu CH, Lane HY, Huang CC. Acute amino acid D-serine administration, similar to ketamine, produces antidepressant-like effects through identical mechanisms. J Agric Food Chem. 2017;65:10792-803.

122. Chen MH, Kao CF, Tsai SJ, CT LI, Lin WC, Hong CJ, et al. Treatment response to low-dose ketamine infusion for treatment resistant depression: a gene-based genome-wide association study. Genomics. 2021;113:507-14.

123. Casarotto PC, Girych M, Fred SM, Kovaleva V, Moliner R, Enkavi G, et al. Antidepressant drugs act by directly binding to TRKB neurotrophin receptors. Cell. 2021;184:1299-313.

124. Zhang K, Yang C, Chang L, Sakamoto A, Suzuki T, Fujita Y, et al. Essential role of microglial transforming growth factor- $\beta 1$ 
in antidepressant actions of $(R)$-ketamine and the novel antidepressant TGF- $\beta 1$. Transl Psychiatry. 2020;10:32.

125. Wei Y, Chang L, Hashimoto K. Intranasal administration of transforming growth factor- $\beta 1$ elicits rapid-acting antidepressantlike effects in a chronic social defeat stress model: A role of TrkB signaling. Eur Neuropsychopharmacol. https://doi.org/ 10.1016/j.euroneuro.2021.04.010 (in press).

126. Dobolyi A, Vincze C, Pal G, Lovas G. The neuroprotective functions of transforming growth factor beta proteins. Int J Mol Sci. 2012;13:8219-58.

127. Caraci F, Spampinato SF, Morgese MG, Tascedda F, Salluzzo MG, Giambirtone MC, et al. Neurobiological links between depression and $\mathrm{AD}$ : the role of TGF- $\beta 1$ signaling as a new pharmacological target. Pharm Res. 2018;130:374-84.

128. Guerrera CS, Furneri G, Grasso M, Caruso G, Castellano S, Drago F, et al. Antidepressant drugs and physical activity: A possible synergism in the treatment of major depression? Front Psychol. 2020;11:857.

129. Sometani A, Kataoka H, Nitta A, Fukumitsu H, Nomoto H, Furukawa $S$. Transforming growth factor- $\beta$ enhances expression of brain-derived neurotrophic factor and its receptor, TrkB, in neurons cultured from rat cerebral cortex. J Neurosci Res. 2001;66:369-76.

130. Musil R, Schwarz MJ, Riedel M, Dehning S, Cerovecki A, Spellmann I, et al. Elevated macrophage migration inhibitory factor and decreased transforming growth factor- $\beta$ levels in major depression-no influence of celecoxib treatment. J Affect Disord. 2011;134:217-25.

131. Rush G, O’Donovan A, Nagle L, Conway C, McCrohan A, O'Farrelly C, et al. Alteration of immune markers in a group of melancholic depressed patients and their response to electroconvulsive therapy. J Affect Disord. 2016;205:60-68.

132. Tombacz D, Maroti Z, Kalmar T, Csabai Z, Balazs Z, Takahashi S, et al. High-coverage whole-exome sequencing identifies candidate genes for suicide in victims with major depressive disorder. Sci Rep. 2017;7:7106.

133. Zhao M, Chen L, Qiao Z, Zhou J, Zhang T, Zhang W, et al. Association between FoxO1, A2M, and TGF- $\beta 1$, environmental factors, and major depressive disorder. Front Psychiatry. 2020;11:675.

134. Abdallah CG, Averill LA, Gueorguieva R, Goktas S, Purohit P, Ranganathan M, et al. Modulation of the antidepressant effects of ketamine by the mTORC1 inhibitor rapamycin. Neuropsychopharmacology. 2020;45:990-7.

135. Monteggia LM, Gideons E, Kavalali ET. The role of eukaryotic elongation factor 2 kinase in rapid antidepressant action of ketamine. Biol Psychiatry. 2013;73:1199-203.

136. Nosyreva E, Szabia K, Autry AE, Ryazanov AG, Monteggia LM, Kavalali ET. Acute suppression of spontaneous neurotransmission drives synaptic potentiation. J Neurosci. 2013;33:6990-7002.

137. Aguilar-Valles A, De Gregorio D, Matta-Camacho E, Eslamizade MJ, Khlaifia A, Skaleka A, et al. Antidepressant actions of ketamine engages cell-specific translation via eIF4E. Nature. 2021;590:315-9.

138. Shi L, Bergson CM. Neuregulin 1: an intriguing therapeutic target for neurodevelopmental disorders. Transl Psychiatry. 2020;10:190.

139. Grieco SF, Qiao X, Johnston KG, Chen L, Nelson RR, Lai C, et al. Neuregulin signaling mediates the acute and sustained antidepressant effects of subanesthetic ketamine. Transl Psychiatry. 2021;11:144.

140. Wong ML, Inserra A, Lewis MD, Mastronardi CA, Leong L, Choo $\mathrm{J}$, et al. Inflammasome signaling affects anxiety- and depressive-like behavior and gut micropbiome composition. Mol Psychiatry. 2016;21:797-805.

141. Rogers GB, Keating DJ, Young RL, Wong ML, Licinio J, Wesselingh S. From gut dysbiosis to altered brain function and mental illness: mechanisms and pathways. Mol Psychiatry. 2016; 21:738-48.

142. Cryan JF, O'Riordan KJ, Cowan CSM, Sandhu KV, Bastiaanssen TFS, Boehme M, et al. The microbiota-gut-brain axis. Physiol Rev. 2019;99:1877-2013.

143. Zheng P, Wu J, Zhang H, Perry SW, Yin B, Tan X, et al. The gut microbiome modulates gut-brain axis glycerophospholipid metabolism in a region-specific manner in a nonhuman primate model of depression. Mol Psychiatry. 2020. https://doi.org/10. 1038/s41380-020-0744-2.

144. Dalile B, Van Oudenhove L, Vervliet B, Verbeke K. The role of short-chain fatty acids in microbiota-gut-brain communication. Nat Rev Gastroenterol Hepatol. 2019;16:461-78.

145. Chang $\mathrm{CH}$, Lin $\mathrm{CH}$, Lane HY. D-glutamate and gut microbiota in Alzheimer's disease. Int J Mol Sci. 2020;21:2676.

146. Yang C, Fujita Y, Ren Q, Ma M, Dong C, Hashimoto K. Bifidobacterium in the gut microbiota confer resilience to chronic social defeat stress in mice. Sci Rep. 2017;7:45942.

147. Zhang K, Fujita Y, Chang L, Qu Y, Pu Y, Wang S, et al. Abnormal composition of gut microbiota is associated with resilience versus susceptibility to inescapable electric stress. Transl Psychiatry. 2019;9:231.

148. Wang S, Qu Y, Chang L, Ou L, Zhang K, Hashimoto K. Antibiotic-induced microbiome depletion is associated with resilience in mice after chronic social defeat stress. J Affect Disord. 2020;260:448-57.

149. Qu Y, Zhang K, Pu Y, Chang L, Wang S, Tan Y, et al. Betaine supplementation is associated with the resilience in mice after chronic social defeat stress: a role of brain-gut-microbiota axis. J Affect Disord. 2020;272:66-76.

150. Wang $\mathrm{S}$, Ishima $\mathrm{T}$, Zhang $\mathrm{J}, \mathrm{Qu} \mathrm{Y}$, Chang $\mathrm{L}, \mathrm{Pu} \mathrm{Y}$, et al. Ingestion of Lactobacillus intestinalis and Lactobacillus reuteri causes depression- and anhedonia-like phenotypes in antibiotictreated mice via the vagus nerve. J Neuroinflammation. 2020; 17:241.

151. Pu Y, Tan Y, Qu Y, Chang L, Wang S, Wei Y, et al. A role of the subdiaphragmatic vagus nerve in depression-like phenotypes in mice after fecal microbiota transplantation from Chrna7 knock-out mice with depression-like phenotypes. Brain Behav Immun. 2021;94:318-26.

152. Yang C, Qu Y, Fujita Y, Ren Q, Ma M, Dong C, et al. Possible role of gut-microbiota in the antidepressant effects of $(R)$-ketamine in a social defeat stress model. Transl Psychiatry. 2017;7:1294.

153. Qu Y, Yang C, Ren Q, Ma M, Dong C, Hashimoto K. Comparison of $(R)$-ketamine and lanicemine on depression-like phenotype and abnormal composition of gut microbiota in a social defeat stress model. Sci Rep. 2017;7:15725.

154. Huang N, Hua D, Zhan G, Li S, Zhu B, Jiang R, et al. Role of Actinobacteria and Coriobacteriia in the antidepressant effects of ketamine in an inflammation model of depression. Pharm Biochem Behav. 2019;176:93-100.

155. Getachew B, Aubee JI, Schottenfeld RS, Csoka AB, Thompson KM, Tizabi Y. Ketamine interactions with gut-microbiota in rats: relevance to its antidepressant and anti-inflammatory properties. BMC Microbiol. 2018;18:222.

156. Wang Y, Xu X, Luo A, Yang C. The role of gut microbiota in the role in the antidepressant effects of ketamine. In "Ketamine: from abused drug to rapid-acting antidepressant", edited by Hashimoto K, Ide S and Ikeda K. Springer Nature; 2020. pp. 127-41.

157. Wei Y, Chang L, Ishima T, Wan X, Ma L, Wuyun G, et al. Abnormalities of the composition of the gut microbiota and short-chain fatty acids in mice after splenectomy. Brain Behav Immun Health. 2021;11:100198.

158. Zhang K, Sakamoto A, Chang L, Qu Y, Wang S, Pu Y, et al. Splenic NKG2D confers resilience versus susceptibility in mice 
after chronic social defeat stress: beneficial effects of $(R)$-ketamine. Eur Arch Psychiatry Clin Neurosci. 2021;271:447-56.

159. Zhang J, Ma L, Chang L, Pu Y, Qu Y, Hashimoto K. A key role of the subdiaphragmatic vagus nerve in the depression-like phenotype and abnormal composition of gut microbiota in mice after lipopolysaccharide administration. Transl Psychiatry. 2020;10:186.

160. Xu D, Zhang Y, Xie B, Yao H, Yuan Y, Yuan S, et al. The spleen mediates chronic sleep restriction-mediated enhancement of LPSinduced neuroinflammation, cognitive deficits, and anxiety-like behavior. Aging. 2020;12:15446-61.

161. Zhang X, Lei B, Yuan Y, Zhang L, Hu L, Jin S, et al. Brain control of humoral immune responses amenable to behavioural modulation. Nature. 2020;581:204-8.

162. Zhang B, Zhong J, Gao Z. A brain-spleen axis regulates humoral immunity. Neurosci Bull. 2021;37:427-9.

163. Yang B, Ren Q, Zhang JC, Chen QX, Hashimoto K. Altered expression of $\mathrm{BDNF}$, BDNF pro-peptide and their precursor proBDNF in brain and liver tissues from psychiatric disorders: rethinking the brain-liver axis. Transl Psychiatry. 2017;7:e1128.

164. Zhang J, Chang L, Pu Y, Hashimoto K. Abnormal expression of colony stimulating factor 1 receptor (CSF1R) and transcription factor PU.1 (SPI1) in the spleen from patients with major psychiatric disorders: A role of brain-spleen axis. J Affect Disord. 2020;272:110-5.

165. Millan MJ, Agid Y, Brüne M, Bullmore ET, Carter CS, Clayton NS, et al. Cognitive dysfunction in psychiatric disorders: characteristics, causes and the quest for improved therapy. Nat Rev Drug Disco. 2012;11:141-68.

166. Krystal JH, Karper LP, Seibyl JP, Freeman GK, Delaney R, Bremner JD, et al. Subanesthetic effects of the noncompetitive NMDA antagonist, ketamine, in humans. Psychotomimetic, perceptual, cognitive, and neuroendocrine responses. Arch Gen Psychiatry. 1994;51:199-214.

167. Passie T, Adams HA, Logemann F, Brandt SD, Wiese B, Karst M. Comparative effects of $(S)$-ketamine and racemic $(R / S)$-ketamine on psychopathology, state of consciousness and neurocognitive performance in healthy volunteers. Eur Neuropsychopharmacol. 2021;44:92-104.

168. Zhou Y, Zheng W, Liu W, Wang C, Zhan Y, Li H, et al. Antidepressant effect of repeated ketamine administration on kynurenine pathway metabolites in patients with unipolar and bipolar depression. Brain behav immun. 2018;74:205-12.

169. Zhou Y, Zheng W, Liu W, Wang C, Zhan Y, Li H, et al. Neurocognitive effects of six ketamine infusions and the association with antidepressant response in patients with unipolar and bipolar depression. J psychopharmacol. 2018;32:1118-26.

170. Shiroma PR, Thuras P, Wels J, Albott CS, Erbes C, Tye S, et al. Neurocognitive performance of repeated versus single intravenous subanesthetic ketamine in treatment resistant depression. J Affect Disord. 2020;277:470-7.

171. Gill H, Gill B, Rodrigues NB, Lipsitz O, Rosenblat JD, ElHalabi $\mathrm{S}$, et al. The effects of ketamine on cognition in treatmentresistant depression: a systematic review and priority avenues for future research. Neurosci biobehav rev. 2020;120:78-85.
172. Chen X, Wang M, Hu Y, Zhan Y, Zhou Y, Zheng W, et al. Working memory associated with anti-suicidal ideation effect of repeated-dose intravenous ketamine in depressed patients. Eur Arch Psychiatry Clin Neurosci. 2021;271:431-8.

173. Tan Y, Fujita Y, Qu Y, Chang L, Pu Y, Wang S, et al. Phencyclidine-induced cognitive deficits in mice are ameliorated by subsequent repeated intermittent administration of $(R)$-ketamine, but not $(S)$-ketamine: role of BDNF-TrkB signaling. Pharm Biochem behav. 2020;188:172839.

174. Goodarzi Z, Mrklas KJ, Roberts DJ, Jette N, Pringsheim T, Holroyd-Leduc J. Detecting depression in Parkinson disease: a systematic review and meta-analysis. Neurology. 2016;87:426-37.

175. Fujita A, Fujita Y, Pu Y, Chang L, Hashimoto K. MPTP-induced dopaminergic neurotoxicity in mouse brain is attenuated after subsequent intranasal administration of $(R)$-ketamine: a role of TrkB signaling. Psychopharmacol. 2020;237:83-92.

176. Kadriu B, Gold PW, Luckenbaugh DA, Lener MS, Ballard ED, Niciu MJ, et al. Acute ketamine administration corrects abnormal inflammatory bone markers in major depressive disorder. Mol Psychiatry. 2018;23:1626-31.

177. Zhang K, Ma M, Dong C, Hashimoto K. Role of inflammatory bone markers in the antidepressant actions of $(R)$-ketamine in a chronic social defeat stress model. Int J Neuropsychopharmacol. 2018;21:1025-30.

178. Xiong Z, Fujita Y, Zhang K, Pu Y, Chang L, Ma M, et al. Beneficial effects of $(R)$-ketamine, but not its metabolite $(2 R, 6 R)$ hydroxynorketamine, in the depression-like phenotype, inflammatory bone markers and bone mineral density in a chronic social defeat stress model. Behav Brain Res. 2019;368:111904.

179. Fujita Y, Hashimoto K. Decreased bone mineral density in ovariectomized mice is ameliorated after subsequent repeated intermittent administration of $(R)$-ketamine, but not $(S)$-ketamine. Neuropsychopharmacol Rep. 2020;40:401-6.

180. Frolkis AD, Vallerand IA, Shaheen AA, Lowerison MW, Swain MG, Barnabe C, et al. Depression increases the risk of inflammatory bowel disease, which may be mitigated by the use of antidepressants in the treatment of depression. Gut. 2019;68: $1606-12$.

181. Lee HS, Lobbestael E, Vermeire S, Sabino J, Cleynen I. Inflammatory bowel disease and Parkinson's disease: common pathophysiological links. Gut. 2021;70:408-17.

182. Fujita Y, Hashimoto Y, Hashimoto H, Chang L, Hashimoto K. Dextran sulfate sodium-induced inflammation and colitis in mice are ameliorated by $(R)$-ketamine, but not $(S)$-ketamine: a role of TrkB signaling. Eur J Pharm. 2021;897:173954.

183. Robinson RG, Jorge RE. Post-stroke depression: a review. Am J Psychiatry. 2016;173:221-31.

184. Xiong Z, Chang L, Qu Y, Pu Y, Wang S, Fujita Y, et al. Neuronal brain injury after cerebral ischemic stroke is ameliorated after subsequent administration of $(R)$-ketamine, but not $(S)$ ketamine. Pharm Biochem Behav. 2020;191:172904.

185. Press release: Perception Neuroscience's PCN-101 (R-ketamine) demonstrates tolerability in phase 1 single ascending dose study. https://www.perceptionns.com/news. 